\title{
SPATIAL AND TEMPORAL VARIATION OF LAND SURFACE TEMPERATURE IN FUJIAN PROVINCE FROM 2001 TO 2015
}

\author{
Yali $\mathrm{Li}^{1 *}$, Xiaoqin Wang, Zhe Ding \\ Key Laboratory of Spatial Data Mining \& Information Sharing of Ministry of Education, National Eng.Research Center of \\ satellite spatial information technology, Fuzhou University, China, $1738911101 @$ qq.com
}

\section{Commission III, ICWG III/Ivc}

KEY WORDS: Land surface temperature, Savitzky Golay (S-G) filter, Slope analysis, Spatial and temporal variations, Fujian province

\begin{abstract}
:
Land surface temperature (LST) is an essential parameter in the physics of land surface processes. The spatiotemporal variations of LST on the Fujian province were studied using AQUA Moderate Resolution Imaging Spectroradiometer LST data. Considering the data gaps in remotely sensed LST products caused by cloud contamination, the Savitzky-Golay (S-G) filter method was used to eliminate the influence of cloud cover and to describe the periodical signals of LST. Observed air temperature data from 27 weather stations were employed to evaluate the fitting performance of the S-G filter method. Results indicate that S-G can effectively fit the LST time series and remove the influence of cloud cover. Based on the S-G-derived result, Spatial and temporal Variations of LST in Fujian province from 2001 to 2015 are analysed through slope analysis. The results show that: 1) the spatial distribution of annual mean LST generally exhibits consistency with altitude in the study area and the average of LST was much higher in the east than in the west. 2) The annual mean temperature of LST declines slightly among 15 years in Fujian. 3) Slope analysis reflects the spatial distribution characteristics of LST changing trend in Fujian.Improvement areas of LST are mainly concentrated in the urban areas of Fujian, especially in the eastern urban areas. Apparent descent areas are mainly distributed in the area of Zhangzhou and eastern mountain area.
\end{abstract}

\section{INTRODUCTION}

As an important parameter of energy exchange between land and atmosphere, LST is the basis for studying regional and global ecological environment and atmospheric science (Salama et al. 2012; Van et al. 2015). The change of LST will change the balance of material energy between the earth's surface and atmosphere, and then influence the change of regional temperature, precipitation, vegetation and other ecological environment (Kerchove et al. 2013; Piao et al. 2014). Satellite remote sensing is an important approach for obtaining LST over wide temporal and spatial ranges(Dong-Li et al. 2016). However, the presence of clouds generates numerous missing and abnormal values that affect the application of LST data (Jia 2014; Xu et al. 2013).In this paper, we chose MODIS $11 \mathrm{~A} 2$ data from Aqua satellites to analyse the Spatial and temporal Variations of LST in Fujian from 2001 to 2015, to overcome LST data missing and reconstruct MODIS LST product, Savizky-Golay (SG) algorithm based on the LST background library is used.

\section{MATERIALS AND METHODS}

\subsection{Study area and data collection}

Fujian province lies in the southeast coast of China with a location of $23^{\circ} 33^{\prime}-28^{\circ} 20^{\prime} \mathrm{N}$ and $115^{\circ} 500^{\prime}-120^{\circ} 40$ 'E (Fig.1). It has geographical characteristics of mountain and hills as well as climatic characteristics of abundant rainfall and frequent rainstorm, which make it complex and changeable of Fujian LST.
To analysis Spatial and temporal Variations of LST in Fujian, a spatial data collection including remote sensing, topography and Meteorological data was constructed. The remote sensing data is an 8-day MODIS LST product (MOD11A2) with a 1-km spatial resolution from 2001-2015 that is derived from AQUA satellites. Topographical data extracted from SRTM DEM. Meteorological ata containing monthly mean temperature from 2001-2015 is derived from China meteorological data network.



Figure 1. The location of study area

\subsection{Savitzky-Golay (S-G) filter method}

Using Savitzky-Golay (S-G) smoothing tool to smooth the MODIS LST time series data, it can effectively remove the influence of cloud, aerosol and outliers in LST data. S-G filter is a weighted sliding average filtering method, and its weight is

\footnotetext{
1 * Yali Li, female, postgraduate, mainly engaged in remote sensing research on natural resources and the environment. Email: 1738911101@qq.com
} 
determined by the number of polynomials of polynomial least squares fitting in the range of a filter window. The S-G filtering process can be represented by the following formula.

$$
\mathrm{Y}_{\mathrm{J}}^{*}=\sum_{\mathrm{i}=-\mathrm{m}}^{\mathrm{i}=\mathrm{m}} \frac{\mathrm{C}_{\mathrm{i}} \mathrm{Y}_{\mathrm{j}+\mathrm{i}}}{\mathrm{N}}
$$

Where, $Y$ is the original sequence $L S T$ value, and $Y^{*}$ is the reconstructed sequence $L S T$ value, $C_{i}$ is the coefficient of $L S T$ value filtering, $N$ means the number of convolution, $m$ is the width of the window, and $j$ is the original $L S T$ array Coefficient.

\subsection{Slope analysis}

Slope analysis is used to simulate different grid variation trends to analyze the spatial variation characteristics of LST in different periods [27].In this paper, slope analysis is used to analyze the spatial annual variation trend of LST. The calculation formula is as follows:

$$
\theta=\frac{\sum_{i=1}^{n} a_{i} b_{i}-\frac{1}{n} \sum_{i=1}^{n} a_{i} \sum_{i=1}^{n} b_{i}}{\sum_{i=1}^{n} b_{i}^{2}-\frac{1}{n}\left(\sum_{i=1}^{n} b_{i}\right)^{2}}
$$

Where, $\theta$ is the change rate of the annual rate; $\mathrm{N}$ is the number of years in the study period from 2001 to $2015 ; b_{i}$ is the time series value, 1 15 respectively represent from 2001 to $2015, a_{i}$ is the mean LST of year i. The temperature change trend was divided into five grades according to the value of the $\theta$, and the rules of the classification were shown in table 1 .

\begin{tabular}{cc}
\hline level & $\theta$ \\
\hline Significantly reduce & $<-0.1$ \\
Slightly reduce & $-0.1 \sim-0.05$ \\
No obvious change & $-0.1 \sim-0.05$ \\
Slightly increase & $0.05 \sim 0.1$ \\
Significantly increase & $>0.1$ \\
\hline
\end{tabular}

Table 1. Classification rules

\section{RESULTS AND ANALYSIS}

\subsection{Reconstruction results validation}

In order to verify the accuracy of the data after s-g reconstruction, the data of 27 meteorological stations in Fujian province were used. And select uniformly covered in Fujian province and contain different altitude eight sites: Pucheng, Fuding, Taning, Fuzhou, Changting, Ninexian mountain, Pingnan, xiamen for the verification results displaying of the air temperature $\left(\mathrm{Ta}^{\circ} / \mathrm{C}\right)$ and LST $(\%)$. The result is shown in the figure 2 .
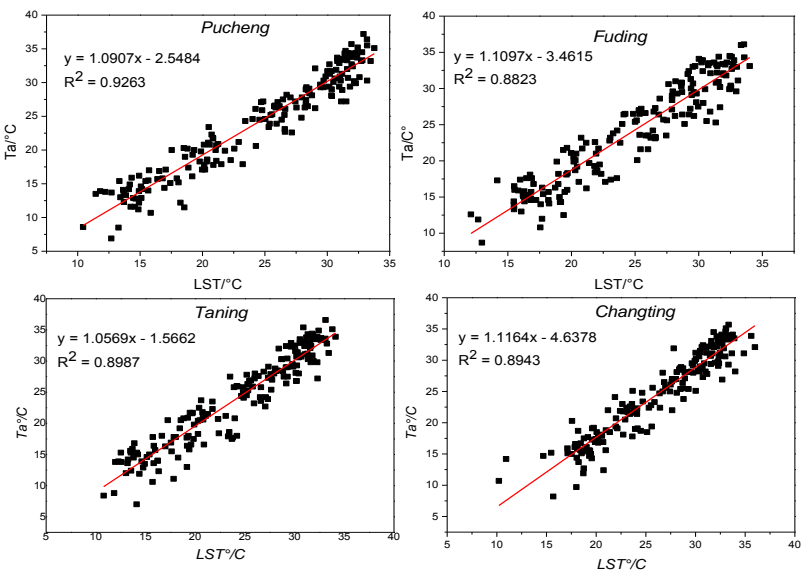
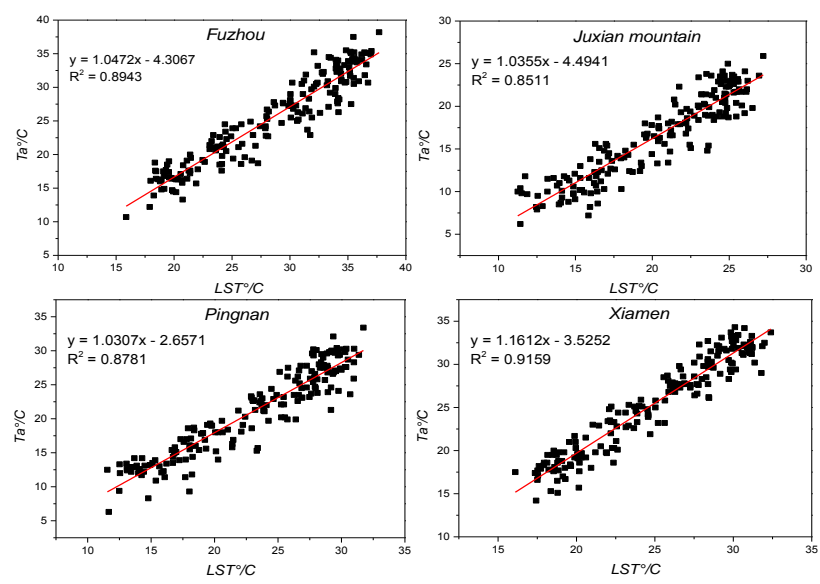

Figure 2. Ta and LST scatter diagram of eight stations.

It can be seen from the scatter diagram that the surface temperature and weather temperature are correlated well, and the reconstruction effect is more reliable.

\subsection{Spatial distribution of land LST}

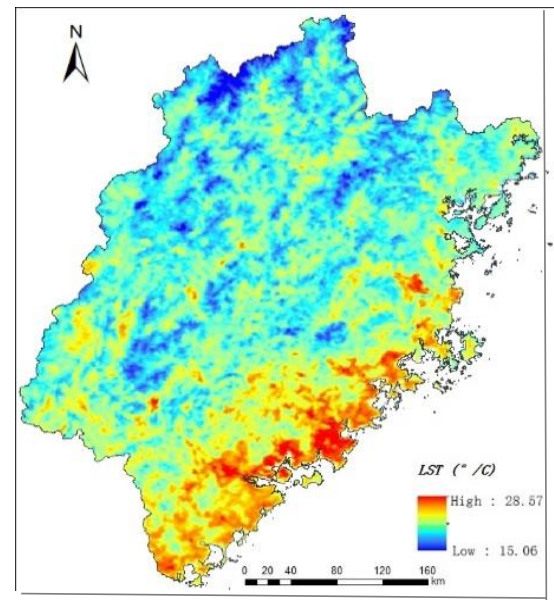

Figure 3. 15 years average LST from 2001 to 2015.

From figure 3 we can see that the LST distribution in Fujian province is unevenly distributed from 2001 to 2015. The annual average LST of the spatial distribution significant differences from 16.05 to $28.57^{\circ} \mathrm{C}$. The eastern coastal temperature as high as $23-28.57^{\circ} \mathrm{C}$, while the Northwest mountain area temperature is $15.06-20^{\circ} \mathrm{C}$. In the southeast coastal such as Xiamen, Putian Fuzhou temperature significantly higher than the surrounding temperature. With the rapid development in recent years, the LST of the urban area is higher than the surrounding temperature. In addition, the temperature change in Fujian province is consistent with that of the mountain range, and the temperature is low at high altitude while it is high at low altitudes. 


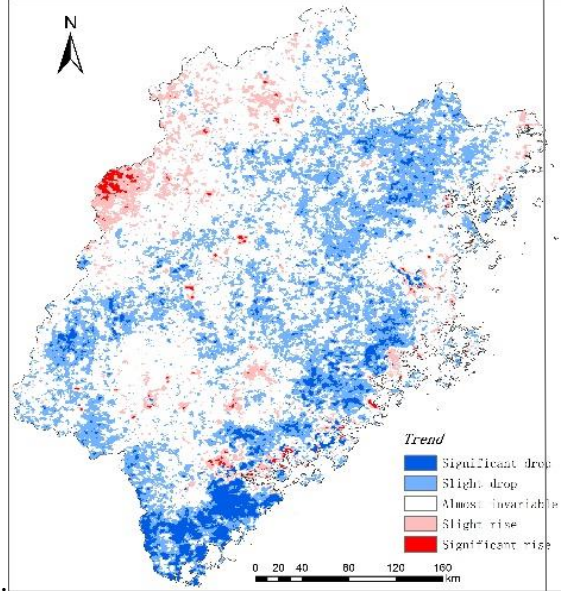

Figure 4. 15 years LST trend from 2001 to 2015

In order to study the variation of LST between 2001 and 2015 in a more intuitive way, slope analysis was used to analyze the variation of surface temperature between 2001 and 2015. From the figure 4 we can see that the temperature drop area in Fujian Province is more than $30 \%$ of the total area of Fujian Province. The area with the most obvious temperature drop is concentrated in Zhangzhou and Changting counties, and the decrease is $-0.43^{\circ}$ $\mathrm{C}$, indicating that Fujian Province In recent years to restore vegetation effect is obvious. While the temperature increase area accounts for about $20 \%$ of the total area, most of which the temperature is slightly increased, the temperature increased significantly in the area mainly concentrated in Xiamen, Putian, Fuzhou and other urban areas and western Jianning County region.

\subsection{Temporal Variations of land LST and vegetation}



Figure 5.Seasonal average temperature and annual average LST change from 2001 to 2015 of Fujian

We take 3-5 months for spring, 6-8 months for summer, 9-11 months for autumn and 12- next February for winter. The total variation of LST spring, summer, autumn and winter in Fujian province from 2001 to 2016 was shown as figure 5. The figure shows that the annual average temperature rise slightly in Fujian province in 2001-2003 and 2006-2009. From 2003-2005 and 2011-2015 the annual average temperature was continue to decline. From the seasons of spring, summer, autumn and winter, the temperature changes in spring, summer, autumn and three seasons are roughly stable, and they wander around $1 \mathrm{C}$ at the average temperature of the season. The average temperature change in winter is more intense, which indicates that the temperature change in Fujian province is unstable in winter. It is easy to be disturbed by external conditions. It also indicates that the climate change in Fujian is more severe in winter.

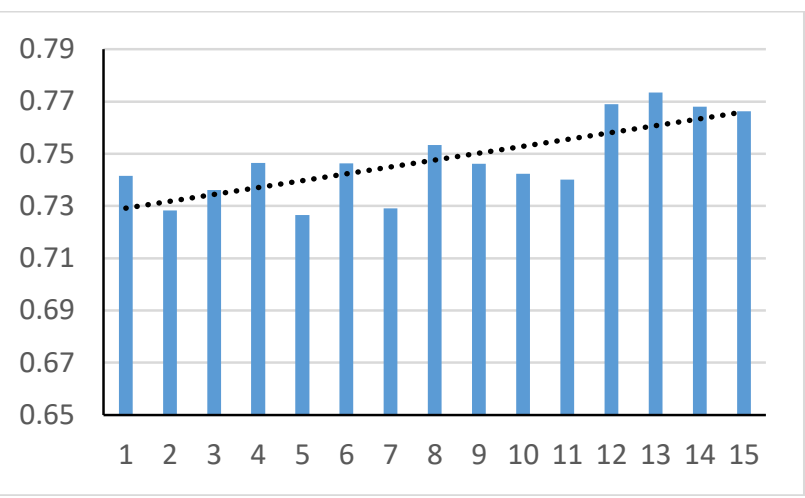

Figure 6. Vegetation change from 2001 to 2015 of Fujian

From fig 6 we can see that the vegetation of Fujan from 2001 to 2015 is slightly increase, especially in the last 4 years from 2012. We all know that vegetation's increase can decrease temperature, so we can conclude that the LST slightly decrease in recently years result from vegetation's increase in a certain way.

\subsection{LST change with altitude}



Figure 7. Radar map of LST change with the coverage different

In order to quantitative analysis the influence of altitude on LST, the altitude is divided into five levels by natural break point classification: below $250 \mathrm{~m}$ is the first level, $250-500 \mathrm{~m}$ is second, $500-750 \mathrm{~m}$ is third, $750-1000 \mathrm{~m}$ is fourth, and above $1000 \mathrm{~m}$ is the fifth(fig 6). From the different levels of altitude, we can see that with the increase of altitude from first level to fifth, the temperature is continue decreasing. However, the decreasing trend in first level to second is different from others two adjacent levels. When the altitude is increasing from first level to second, the temperature is decreasing $2 \mathrm{C}$, but when the altitude is greater than second level, with the altitude going on to the next level the temperature is decreasing about 1 . C, about.1/2 times decreasing degree from first level to second. From (fig 6) we can conclude that the decrease tendency of temperature with the increase of altitude is the same in different years and as to the effects of human activity the LST in low altitude regions are increase.

\section{CONCLUSIONS}

(1).In this paper, the spatiotemporal variations of daytime LST in the Fujian province were studied using AQUA MODIS 1-km LST data from 2001 to 2015 . The S-G was introduced to suppress cloud contamination and discriminate significant 
periodic variations of LST. Evaluation results indicate that the S$\mathrm{G}$ fliter can provide satisfactory fitting for the LST time series and eliminate the influence of cloud cover on the remotely sensed LST data.

(2).From 2001 to 2015, the overall temperature of Fujian decreased, and the temperature reached the highest in 2009, and the temperature decreased after 2009 , which was related to the improvement of vegetation restoration in Fujian province.

(3).LST drop area of Fujian province in recent years in Fujian province is more, about $30 \%$ of the total area of Fujian province, the temperature drops concentrated in Zhangzhou and Changting county, one of the most obvious area decreased to $0.43{ }^{\circ} \mathrm{C}$, because of obvious effects of Fujian province in recent years to restore vegetation. And elevated temperature region accounted for about $20 \%$ of the total area, most of which temperature is slightly growth, temperature rise obvious area mainly concentrated in Fuzhou, Xiamen, Putian, such as urban areas and the western area set up rather county. For spring, summer, autumn and winter, the temperature change in winter is unstable, and it is easy to be disturbed by the outside world and extreme weather occurs.

\section{ACKNOWLEDGEMENTS}

This work was supported by National key research and development project Fund under Grant No.20017YFB0504203 and the Central Government Guides Local Development Special Fund under Grant No. 2017L3012.

\section{REFERENCES}

Dong-Li, G.U., Yin-Cui, H.U., \& Wang, B. (2016). Analysis of Spatial-temporal Changes of Vegetation in Hebei Province and Its Influential Factors Based on MODIS / NDVI and Its Affecting Factors. Hubei Agricultural Sciences

Jia, H.J. (2014). Analysis of the ecological environment changes in land surface temperature, and NDVI based on MODIS remote sensing data. Remote Sensing Information, 2014, 855-856

Kerchove, V.D., Goossens, Lhermitte, \& Veraverbeke (2013). Spatio-temporal variability in remotely sensed land surface temperature,;and its relationship with physiographic variables in the Russian Altay;Mountains. International Journal of Applied Earth Observation \& Geoinformation, 20, 4-19

Piao, S., Nan, H., Huntingford, C., Ciais, P., Friedlingstein, P., Sitch, S., Peng, S., Ahlström, A., Canadell, J.G., \& Cong, N. (2014). Evidence for a weakening relationship between interannual temperature variability and northern vegetation activity. Nature Communications, 5, 5018

Salama, M.S., Velde, R.V.D., Zhong, L., Ma, Y., Ofwono, M., \& $\mathrm{Su}, \mathrm{Z}$. (2012). Decadal variations of land surface temperature anomalies observed over the Tibetan Plateau by the Special Sensor Microwave Imager (SSM/I) from 1987 to 2008. Climatic Change, 114, 769-781

Van, N.O., Kawamura, K., Trong, D.P., Gong, Z., \& Suwandana, E. (2015). Temporal change and its spatial variety on land surface temperature and land use changes in the Red River Delta, Vietnam, using MODIS time-series imagery. Environmental Monitoring \& Assessment, 187, 1-11
Xu, Y., Shen, Y., \& Wu, Z. (2013). Spatial and Temporal Variations of Land Surface Temperature Over the Tibetan Plateau Based on Harmonic Analysis. Mountain Research \& Development, 33, 85-94 